\title{
Simulation Studies for Motion Control of Multiple Biohybrid Microrobots in Human Synovial Fluid with Discontinuous Reference Signals
}

\author{
Süreksiz Referans Sinyalleri ile Insan Sinovyal Sivısında Birden Fazla Biyohibrit \\ Mikrorobotun Hareket Kontrolü için Benzetim Çalışmaları
}

\author{
Ahmet Fatih TABAK ${ }^{1}$ \\ ${ }^{1}$ Kadir Has University, Mechatronics Engineering, 34083 Istanbul, Turkey
}

\begin{abstract}
It is envisioned that biomedical swarms are going to be used for therapeutic operations in the future. The utilization of a single robot in live tissue is not practical because of the limited volume. In contrast, a large group of microrobots can deliver a useful amount of potent chemicals to the targeted tissue. In this simulation study, a trio of magnetotactic bacteria as a taskforce, Magnetospirillum Gryphiswaldense MSR-1, is maneuvered via adaptive micro-motion control through an external magnetic field. The magnetic field is induced by a single permanent magnet positioned by an open kinematic chain. The coupled dynamics of this small group in the human synovial tissue is simulated with actual magnetic and fluidic properties of the synovial liquid. The common center of mass is tracked by the equation of motion. The overall hydrodynamic interaction amongst all three bacteria is modeled within a synovial medium confined with flat surfaces. A bilateral control scheme is implemented on top of this coupled model. The position of the common center of mass is used as the reference point to the end-effector of the robotic arm. The orientation of the magnetic field is rotated to change the heading of the bacterial-group in an addressable manner. It has been numerically observed that controlling the common swimming direction of multiple bacteria is fairly possible. Results are presented via the rigid-body motion of the robotic task-force as well as the fluidic and magnetic force-components acting on the bacteria along with the bilateral control effort in all axes.

Keywords: Micro-Motion Control, Synovial Fluid, Magnetotactic Bacterium, Multiscale Robots, Bilateral Control, Adaptive
\end{abstract} Control

Öz

Gelecekte mikro robotik sürülerin medikal operasyonlar için kullanılması öngörülmektedir. Canlı dokuda tek bir mikro robotun kullanılması, sınırlı hacim nedeniyle pratik değildir. Ancak, kalabalık bir mikro robot grubu, hedeflenen dokuya yararlı miktarda faydalı kimyasallar iletebilir. Bu simülasyon çalışmasında, bir görev gücü olarak seçilen üç manyetotaktik bakterinin (Magnetospirillum Gryphiswaldense MSR-1) harici bir manyetik alan aracılığıyla adaptif mikro-hareket kontrol performansı araştırılmıştır. Manyetik alan, üç serbestlik dereceli açık bir kinematik zincir tarafından konumlandırılan tek bir doğal Neodimyum mıknatıs yardımı ile oluşturulur. Açık kinematik zincirin her ekseninde adanmış bir doğru akım (DC) motoru bulunmaktadır. İnsan sinovyal ekleminde hareket eden bu küçük bakteri grubunun katı cisim dinamikleri, sinovyal sıvının gerçek manyetik ve akışkan özellikleri üzerinden simüle edilir. Mikro robotların ortak kütle merkezi, hareket denklemi ile izlenir. Üç bakteri arasında hareket sırasında ortaya çıkan çapraz hidrodinamik etkileşim, sinovyal sıvı sınırları içinde modellenmiş̧tir. Ortaya çıkan sistem dinamiklerinin üstüne çift yanlı bir adaptif kontrol yaklaşımı ile referans sinyali uygulanmaktadır. Ortak kütle merkezinin konumu, açık kinematik zincirin uç efektörüne referans noktası olarak geri beslenmektedir. Manyetik alanın yönü, bakteri grubunun yönünü adreslenebilir bir şekilde değiştirmek için kullanılmaktadır. Üç bakteriden oluşan bu görev gücünün ortak yüzme yönünü, sinovyal sıvı içerisinde ayrık kontrol sinyalleri ve adaptif kontrol çalışması ile idare etmenin kısmen mümkün olduğu, farklı referans fonksiyonları yardımı ile, sayısal olarak gözlenmiştir. Sonuçlar, robotik görev gücünün katı cisim hareketi ve tüm eksenlerde mevcut çift taraflı kontrol çabasına ek olarak bakterilere etki eden akışkan ve manyetik kuvvet bileşenleri aracıllı̆̆ıla sunulur.

Anahtar Kelimeler: Mikro-Hareket Kontrolü, Sinovyal Sıvı, Magnetotaktik Bakteri, Çok Ölçekli Robotlar, Çift Yanlı Kontrol, Adaptif Kontrol

\section{INTRODUCTION}

The field of biomedical micro-robotics is perceived as a promising interdisciplinary field of medical science, robotic applications, and microtechnology drawing much attention for the past two decades [1-10]. The envisioned tasks for biomedical microrobots include kidney stone destruction, removal of blood-clots, targeting cancerous cells, and carrying potent chemicals to predefined locations [11,12]. The materials and approaches used include manufacturing artificial swimmers using organic materials [13] and inorganic materials [14,15], incorporating live cells into biohybrid systems [16,17], and directly employing self-propelling single-celled organism within the robotic system $[18,19]$. One very important benefit of the latter approach is biocompatibility for biomedical applications. 
The biological well-being of the living organism is of the utmost importance. Therefore, the robotic device should be able to carry out the therapeutic task without any unforeseen complications in the living tissue. The strategy of relying on biocompatibility is the way to reduce the possibility of the immune system attacking the micro-robotic device or avoiding the possible toxic effects of the materials used in micro and nanomanufacturing processes [20-22]. The use of patientbased organic materials [23] and modified live cells [24], amongst other alternative solutions [25,26], are devised to address this practical but crucial problem. The use of natural cells in a robotic system causes a paradigm shift since power supply and motion control turn out to be detached issues as opposed to fully artificial systems. Furthermore, there are recent studies on micro-motion control in synovial liquid using biocompatible microrobots of different origins [27,28], most of which focus on incorporating magnetotactic bacteria in the complex medium.

In addition, groups of micro swimmers are being considered for the therapeutic applications [29-35]. Single microrobots are not capable of carrying substantial amounts of potent chemicals, nor on-boards sensory equipment can be incorporated. Thus, tracking and control of a single microrobot stands as a challenge whereas a large group can be tracked relatively more easily. Moreover, it will be possible to employ individual groups for different tasks simultaneously [36-38]. Finally, if the swarm is composed of biohybrid robots, energy supply problem could arguably be partially solved. The aforementioned reasons make swarm research more appealing for future studies.

There are several control studies in the literature demonstrating the performance of magnetotactic bacteria species Magnetospirillum Gryphiswaldense MSR-1 via electromagnetic (EM) coils and permanent magnets. The former approach demonstrating nonadaptive control effort on the swimming direction of real bacterium samples $[39,40]$ while the latter investigating the adaptive control approach on the simulated bacterium and environment with continuous or discontinuous reference signals [28, 41-45]. In this study, a rudimentary control scheme for a biohybrid robotic system is numerically demonstrated with the help of a discontinuous set point yaw-angle reference using basic ramp and step functions. The reported studies in the literature are based on in vitro swimming conditions of $M$. Gryphiswaldense MSR-1 in an aqueous medium [39-45] and in vivo performance in the synovial liquid [28], however, acting as a single microrobot in the fluidic medium.

In this study, a swarm of three Magnetospirillum Gryphiswaldense MSR-1 is being controlled as a task force in the synovial liquid offering a novel analysis to the literature of biomedical micro-robotic research. The model and simulation strategy is based on previous studies $[28,41]$ by expanding the analysis to swarms. Here, a detailed mathematical model representing the coupled system of an open kinematic chain, the task force of three magnetotactic bacteria, and one permanent magnet is cast to simulate the rigid-body and control dynamics of all the systems. Adaptive integral gains are incorporated in the proportionalintegral-derivative (PID) control scheme. The control scheme is constructed to be bilateral; resulting in a two-way coupled system. Furthermore, two timedependent reference functions are used to rotate the bacteria in clockwise and counter-clockwise directions, on separate occasions. The Methodology section discusses the details on the mathematical model of the system and the adaptive control followed by the Results section presenting the performance of the control algorithm and the prospect of controlling multiple bacteria in vivo.

\section{METHODOLOGY}

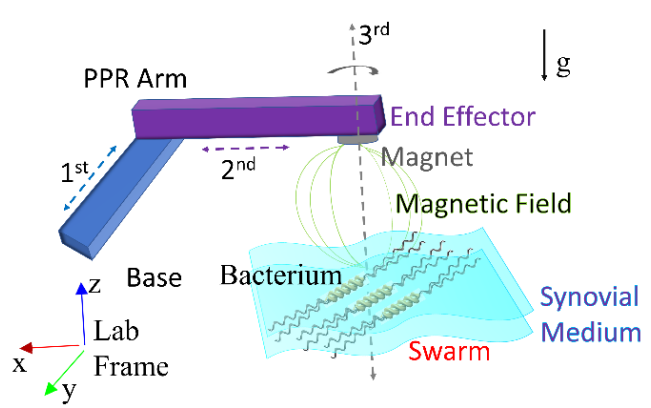

Figure 1. PPR arm, the swarm comprised of three neutrally buoyant magnetotactic bacteria, the magnet at the end of the open kinematic chain, the magnetic field

between the magnet and the swarm, the synovial medium of a certain thickness, gravitational attraction.

Figure 1 depicts the robotic system with the open kinematic chain, i.e. the prismatic-prismatic-revolute (PPR) robotic arm, the neutrally-buoyant group of bacteria, i.e., three hydrodynamically coupled Magnetospirillum Gryphiswaldense MSR-1 [39,40], and one $0.02 \times 0.02 \times 0.02 \mathrm{~m}^{3}$ permanent magnet, i.e., the N52-grade Neodymium [46] block, located at the endeffector of the robotic arm. The robotic arm is oriented in the workspace such that the magnet can traverse along the xy-plane and revolve along the z-axis in the lab frame. Each joint of the PPR arm is articulated by a dedicated brushless DC-motor [47]. The first two links of the PPR arm are selected to be aluminum prisms of $5 \times 5 \times 30 \times 10^{-6} \mathrm{~m}^{3}$. The axes of the arm do not interact with gravitational attraction and are assumed to be rigid enough to withstand deformation along z-axes against own weight. The motion of the end-effector is assumed to be undisturbed by possible impurities in the construction of the open kinematic chain.

Each bacterium cell has two helical bundles consisting of two flagella each, articulated on the opposite sides 
of its cell body $[39,40]$. The magnetic field penetrates the synovial liquid. As the magnet rotates, the resultant time-dependent magnetic field or the resultant electromagnetic field (EMF in Figure 2) exerts the torque necessary to change the yaw-angle of the swarm. The swarm propels itself fully submerged in the synovial liquid at body temperature.

In this study, each bacterium is simulated as a separate robot. They are far enough from each other so that they can swim in formation. Therefore, each bacterium has its equation of motion given as:

$\left[\begin{array}{c}\mathbf{F}_{p}(t)+\mathbf{F}_{m}(t)+\mathbf{F}_{d}(t)+\sum_{j, k} \mathbf{F}_{s w}(t)+\mathbf{F}_{c}(t) \\ \mathbf{T}_{p}(t)+\mathbf{T}_{m}(t)+\mathbf{T}_{d}(t)+\sum_{j, k} \mathbf{T}_{s w}(t)+\mathbf{T}_{c}(t)\end{array}\right]_{i}$

$$
=\mathbf{0}
$$

with subscripts ' $p$ ', ' $m$ ', ' $d$ ', 'sw', and ' $c$ ' denoting the total propulsive effect of the tails (Equation (2)), the stimulation of the Neodymium magnet (Equation (3), the viscous drag on the surface of the bacterium (Equation (4)), the hydrodynamic cross-coupling with the other two bacteria in the swarm (Equation (5)), and the contact with the solid boundary (Equation (6)), respectively. Also, the subscripts ' $i$ ', ' $j$ ', and ' $k$ ' denote the individual bacterium in the swarm.

The propulsive effect is modeled by integrating the local resistive force acting on the tails as:

$$
\begin{aligned}
& {\left[\begin{array}{c}
\mathbf{F}_{p} \\
\mathbf{T}_{p}
\end{array}\right]=} \\
& \left(\begin{array}{r}
L_{1}^{4} \\
0
\end{array}\left[\begin{array}{cc}
\mathbf{R}_{1} \mathbf{C}_{1} \mathbf{R}_{1}^{\mathrm{T}} & -\mathbf{R}_{1} \mathbf{C}_{1} \mathbf{R}_{1}^{\mathrm{T}} \mathbf{S}_{1} \\
\mathbf{S}_{1} \mathbf{R}_{1} \mathbf{C}_{1} \mathbf{R}_{1}^{\mathrm{T}} & -\mathbf{S}_{1} \mathbf{R}_{1} \mathbf{C}_{1} \mathbf{R}_{1}^{\mathrm{T}} \mathbf{S}_{1}
\end{array}\right] \mathrm{d} \ell\right)\left[\begin{array}{c}
\mathbf{0} \\
\boldsymbol{\Omega}_{\text {tail }}
\end{array}\right] \\
& +\left(2 \int_{0}^{L_{2}}\left[\begin{array}{cc}
\mathbf{R}_{2} \mathbf{C}_{2} \mathbf{R}_{2}^{\mathrm{T}} & -\mathbf{R}_{2} \mathbf{C}_{2} \mathbf{R}_{2}^{\mathrm{T}} \mathbf{S}_{2} \\
\mathbf{S}_{2} \mathbf{R}_{2} \mathbf{C}_{2} \mathbf{R}_{2}^{\mathrm{T}} & -\mathbf{S}_{2} \mathbf{R}_{2} \mathbf{C}_{2} \mathbf{R}_{2}^{\mathrm{T}} \mathbf{S}_{2}
\end{array}\right] \mathrm{d} \ell\right)\left[\begin{array}{c}
\mathbf{0} \\
\boldsymbol{\Omega}_{\text {tail }_{2}}
\end{array}\right]
\end{aligned}
$$

Equation (2) calculates the 6-degrees-of-freedom propulsion force and torque vectors $[48,49]$ with the help of $3 \times 3$ matrices; $\mathbf{R}$ giving the rotation matrix for local Frenet-Serret coordinates, $\mathbf{S}$ representing the local cross-products, and $\mathbf{C}$ containing the local fluid resistance coefficients for the tails.

The magnetic force and torque vectors on each bacterium cell are denoted by:

$\left[\begin{array}{c}\mathbf{F}_{m} \\ \mathbf{T}_{m}\end{array}\right]=\left[\begin{array}{c}(\mathbf{m} \cdot \nabla)\left(\mathbf{R}_{m a g} \mathbf{B}\right) \\ \mathbf{m} \times\left(\mathbf{R}_{m a g} \mathbf{B}\right)\end{array}\right]$

with $\mathbf{m}$ signifying the magnetic moment possessed by the bacterium [40], $\mathbf{B}$ is the magnetic field felt by the bacterium, i.e., $\mathbf{B}=\left[\begin{array}{lll}B_{x} & B_{y} & B_{z}\end{array}\right]^{\mathrm{T}}$, and $\mathbf{R}_{m a g}$, is the rotation matrix between the bacterium and the end effector of the arm. Furthermore, the components of $\mathbf{B}$ are calculated based on the position of each bacterium, i.e., $\left[\begin{array}{lll}x & y & z\end{array}\right]^{\mathrm{T}}$ relative to the position of the magnet in the lab frame [41]. Thus, each bacterium is under the influence of different magnetic fields and fieldgradients.

The viscous drag acting against the resultant translational and rotational rigid-body velocity, i.e., [U $\mathbf{\Omega}]_{s w}^{\mathrm{T}}$, is given in Equation (6):

$\left[\begin{array}{l}\mathbf{F}_{d} \\ \mathbf{T}_{d}\end{array}\right]=-\left\{2 \int_{0}^{L_{1}}\left[\begin{array}{cc}\mathbf{R}_{1} \mathbf{C}_{1} \mathbf{R}_{1}^{\mathrm{T}} & -\mathbf{R}_{1} \mathbf{C}_{1} \mathbf{R}_{1}^{\mathrm{T}} \mathbf{S}_{1} \\ \mathbf{S}_{1} \mathbf{R}_{1} \mathbf{C}_{1} \mathbf{R}_{1}^{\mathrm{T}} & -\mathbf{S}_{1} \mathbf{R}_{1} \mathbf{C}_{1} \mathbf{R}_{1}^{\mathrm{T}} \mathbf{S}_{1}\end{array}\right] \mathrm{d} \ell\right.$

$+2 \int_{0}^{L_{2}}\left[\begin{array}{cc}\mathbf{R}_{2} \mathbf{C}_{2} \mathbf{R}_{2}^{\mathrm{T}} & -\mathbf{R}_{2} \mathbf{C}_{2} \mathbf{R}_{2}^{\mathrm{T}} \mathbf{S}_{2} \\ \mathbf{S}_{2} \mathbf{R}_{2} \mathbf{C}_{2} \mathbf{R}_{2}^{\mathrm{T}} & -\mathbf{S}_{2} \mathbf{R}_{2} \mathbf{C}_{2} \mathbf{R}_{2}^{\mathrm{T}} \mathbf{S}_{2}\end{array}\right] \mathrm{d} \ell$

$$
\left.+\int_{0}^{L_{b o d y}}\left[\begin{array}{cc}
\mathbf{R}_{b} \mathbf{C}_{b} \mathbf{R}_{b}^{\mathrm{T}} & -\mathbf{R}_{b} \mathbf{C}_{b} \mathbf{R}_{b}^{\mathrm{T}} \mathbf{S}_{b} \\
\mathbf{S}_{b} \mathbf{R}_{b} \mathbf{C}_{b} \mathbf{R}_{b}^{\mathrm{T}} & -\mathbf{S}_{b} \mathbf{R}_{b} \mathbf{C}_{b} \mathbf{R}_{b}^{\mathrm{T}} \mathbf{S}_{b}
\end{array}\right] \mathrm{d} \ell\right\}\left[\begin{array}{l}
\mathbf{U} \\
\boldsymbol{\Omega}
\end{array}\right]_{s w}
$$

with $\mathbf{S}_{b}$ being the skew-symmetric matrix for the center of volume of the body of the bacterium.

The hydrodynamic cross-coupling effect, i.e., the hydrodynamic interaction (HDI in Figure 2), is calculated by [50]:

$$
\left[\begin{array}{c}
\mathbf{F}_{s w}(t) \\
\mathbf{T}_{s w}(t)
\end{array}\right]=\left[\begin{array}{c}
\frac{100 e^{-100 h_{p} t}}{1-e^{-100 h_{p} t}} \mathbf{d}_{p}(t) \\
\mathbf{p}_{d}(t) \times \mathbf{F}_{s}(t)
\end{array}\right]
$$

with $h_{p}(t)$ being the proximity between the opposite surfaces of two bacteria, the vector $\mathbf{d}_{p}(t)$ denoting the common normal between the closest points on the opposite surfaces, and $\mathbf{p}_{p}(t)$ giving the location of the closest point on the surface in the inertial frame of each bacterium [50].

The contact force ( $\mathrm{CF}$ in Figure 2) acting on each bacterium cell should a collision with the solid boundary occurs is modeled based on the penalty approach [51] as:

$\left[\begin{array}{l}\mathbf{F}_{c} \\ \mathbf{T}_{c}\end{array}\right]=$

$\left[\begin{array}{cc}\delta \Leftarrow \delta<=0 \\ \left.k \begin{array}{c}\delta \\ 0 \Leftarrow 0\end{array} \quad \begin{array}{c}\mathrm{d} \delta / \mathrm{d} t \Leftarrow \mathrm{d} \delta / \mathrm{d} t>0 \\ 0 \Leftarrow \mathrm{d} \delta / \mathrm{d} t<=0\end{array}\right) \mathbf{n}_{c} \\ \mathbf{S}_{c} \mathbf{F}_{c}\end{array}\right]$

with necessary conditions imposed associated with the girid-body motion in lab frame.

In Equation (6), $\delta$ is the penetration depth, $k$ and $b$ represent the stiffness and damping at the point of 
contact, respectively, where exists a surface normal, $\mathbf{n}_{c}$, employed to calculate the direction of contact force. Finally, $\mathbf{S}_{c}$ denotes the skew-symmetric matrix for the position of the point of contact in the inertial frame of the bacterium.

It must be noted that the matrices $\mathbf{C}_{\{1,2, b\}}$ in Equations (2) and (4) are diagonal [41-45] and contain the viscosity of the synovial fluid, $\mu$, that is responsible for the lubrication of the synovial joint and exhibits non-Newtonian, i.e., shear-thinning, behavior [52,53]. The shear-thinning effect of the viscosity is given by:

$\mu=0.4814(2 \pi f)^{0.385}-0.07142 / 2 \pi f$

with $f$ being the rotation frequency of the helical tails, $471.2 \mathrm{rad} / \mathrm{s}$ as reported [40].

The dynamics of the PPR arm [51] can be presented by Equation (8) given that the proposed open kinematic chain is not susceptible to gravity, Coriolis, and centrifugal forces due to its simple design and orientation in the lab frame:

$\mathbf{D} \ddot{\mathbf{q}}=\mathbf{K}_{m} \mathbf{I}_{m}$

with $\mathbf{D}$ being the mass matrix of the PPR-arm [41]. The vector $\mathbf{q}$ denotes the generalized coordinates, $\mathbf{q}=$ $\left[\begin{array}{lll}\mathrm{d}_{1}(t) & \mathrm{d}_{2}(t) & \theta_{3}(t)\end{array}\right]^{\mathrm{T}}$ along which the motion of the respective joint takes place. The Denavit-Hartenberg table [51] representing the link constants and joint variables is given in Table 1. Finally, $\mathbf{I}_{m}$ is the diagonal matrix of the motor currents leading to coupled electromechanics for the robotic arm as the motor current also appears in the electromechanical equations of the DC-motors.

Table I. Denavit-Hartenberg table of the PPR open kinematic chain arm depicted in Figure 1.

\begin{tabular}{|c|c|c|c|c|}
\hline $\begin{array}{c}\text { Link/ } \\
\text { Joint }\end{array}$ & $\begin{array}{c}\text { Twist } \\
\text { angle } \\
(\mathbf{r a d})\end{array}$ & $\begin{array}{c}\text { Link } \\
\text { length } \\
(\mathbf{m})\end{array}$ & $\begin{array}{c}\text { Offset } \\
(\mathbf{m})\end{array}$ & $\begin{array}{c}\mathbf{z -} \\
\text { Rotation } \\
(\mathbf{r a d})\end{array}$ \\
\hline $1^{\text {st }}$ & $-\pi / 2$ & 0 & $\mathrm{~d}_{1}(t)$ & 0 \\
\hline $2^{\text {nd }}$ & $-\pi / 2$ & 0 & $\mathrm{~d}_{2}(t)$ & $\pi / 2$ \\
\hline $3^{\text {rd }}$ & 0 & 0 & 0.02 & $\theta_{3}(t)$ \\
\hline
\end{tabular}

Each one of the dedicated DC-motors is represented by a mathematical model of the form [51]:

$$
L_{m} \dot{I}_{m}+R_{m} I_{m}=V_{m}-K_{b} \dot{q}_{m}
$$

with $I_{m}$ standing for the motor current, $V_{m}$ denoting the applied control voltage, $L_{m}$ and $R_{m}$ representing the inductance and resistance of the DC-motor, respectively, and $K_{b}$ being the back-emf constant of the armature. All motor specifications used in this study are of the Maxon EC 45 Flat brushless $48 \mathrm{~V}$ \& $70 \mathrm{~W}$ DC-motor [47]. The brushless DC-motors are selected based on the previous numerical simulation studies [28, 41-45].

Equation (8) and Equation (9) are solved together to find the acceleration of each joint and the corresponding DC-motor currents as a linear system of coupled equations. Time derivatives of link velocities and motor currents are determined following the respective control input, $V_{m}$, while satisfying the electromechanical constraints, e.g., upper limits of continuous current and velocity [47]. Position in the lab frame and the currents are predicted via simple integration over time.

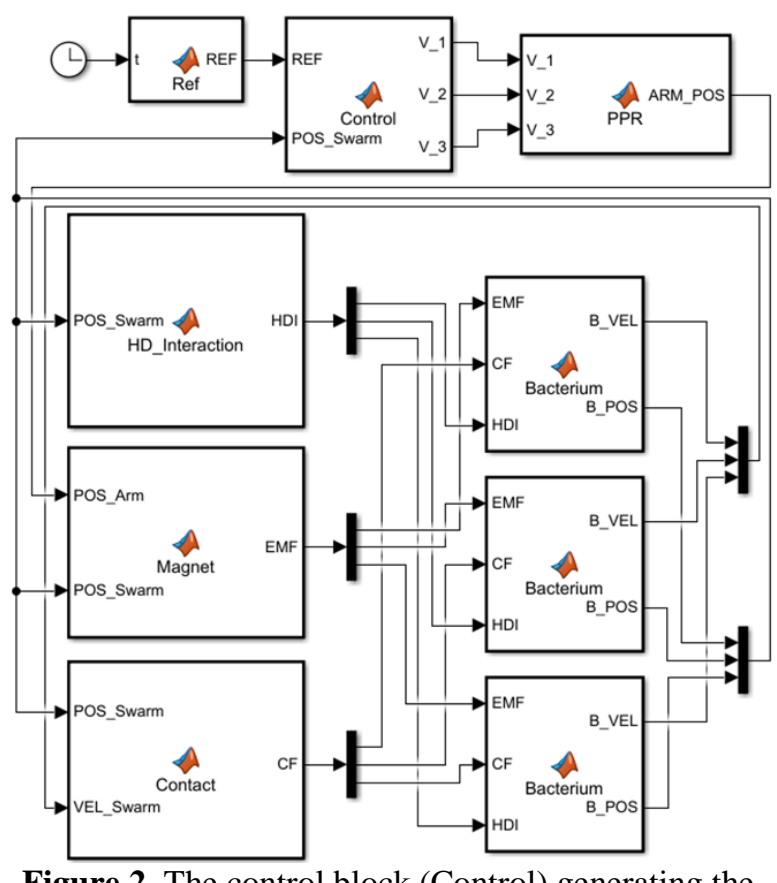

Figure 2. The control block (Control) generating the voltage values to the DC-motors on the PPR arm (PPR) based on the reference (REF) and swarm position (POS_Swarm). The arm position (ARM_POS) the magnet (Magnet), Magnet generates the field on each bacterium (Bacterium), each Bacterium interacts with each other (HD_Interaction) and the surrounding boundary (Contact). The position and velocity of each bacterium are denoted by B_POS and B_VEL, respectively.

The control loop and the system, which are constructed in MATLAB/SIMULINK environment, are depicted in Figure 2. The instantaneous position of each robot is averaged and used as a position reference to the PPR arm. Also, the average of the instantaneous $\mathrm{z}$-angle of the bacterial swarm is used to calculate the yaw-angle error. The control law for the entire system to ensure the yaw-angle reference tracking with reasonable error is given as:

$$
\begin{aligned}
& \tau_{\{x, y, z\}}=K_{p-\{x, y, z\}} e_{\{x, y, z\}}(t) \\
& +\int K_{i-\{x, y, z\}} e_{\{x, y, z\}}(t) \mathrm{d} t+K_{d-\{x, y, z\}} \dot{e}_{\{x, y, z\}}(t)
\end{aligned}
$$


with

$$
K_{i-\{x, y, z\}}=1 /\left(\left(K_{i a-\{x, y, z\}} e_{\{x, y, z\}}(t)\right)^{2}+1\right)
$$

constituting the adaptive component.

Here, the coefficients $K_{p-\{x, y, z\}}$, and $K_{d-\{x, y, z\}}$ are the proportional and derivative gains for the PID employed in this study. Furthermore, the integral gain, $K_{i-\{x, y, z\}}$, is designed as an adaptive gain [28,41-45] dependent on a separate tuning parameter, $K_{i a-\{x, y, z\}}$. $K_{i a-\{x, y, z\}}$ is presented with a different power on the denominator to further modify its effect as opposed to previous studies [28,41-45], and it is possible to modify the term further to change the behavior of the adaptive contribution of the integral although not studied in this work.

The error functions, $e_{\{x, y, z\}}(t)$, for the joints is given as $e_{x}(t)=\left\langle y_{s w}(t)\right\rangle-\mathrm{d}_{2}(t), e_{y}(t)=\left\langle x_{s w}(t)\right\rangle-\mathrm{d}_{1}(t)$, and $e_{z}(t)$ $=\theta^{r e f}(t)-\left\langle\theta_{z-s w}(t)\right\rangle$. The bilateral control coerces the PPR-arm to follow the swarm while inducing the torque on the bacteria necessary to align with the yawangle reference thus coupling the dynamics of the multiscale robotic system. Once the control signal, $\tau_{\{x, y, z\}}$, is determined the corresponding pulse-widthmodulation (PWM) signal generation follows [28]. The PWM signal is finally amplified to the nominal voltage of the DC-motors for operation, i.e. $\pm 48 \mathrm{~V}$ [47] and fed back in Equation (9) to complete the closed-loop control depicted in Figure 2.

\section{RESULTS AND DISCUSSION}

The following results are obtained for two separate reference functions given by the combination of two ramp functions and one step function as $\theta^{\text {ref }}(t)=$ $-(\pi / 18) \cdot t \cdot(t>=0) \cdot(t<1)-(\pi / 18) \cdot(t>=1) \cdot(t<2)$ $+(\pi / 18) \cdot t \cdot(t>=2) \cdot(t<3)$ rad for clockwise rotation and $\theta^{r e f}(t)=(\pi / 18) \cdot t \cdot(t>=0) \cdot(t<1)+(\pi / 18) \cdot(t>=1) \cdot(t$ < 2) $-(\pi / 18) \cdot t \cdot(t>=2) \cdot(t<3) \mathrm{rad}$ for counterclockwise rotation. The bacteria are initially located on the same xy-plane as depicted in Figure 1 and their relative location with respect to each other are given as $\left[\begin{array}{lll}0 & 0 & 0\end{array}\right]^{\mathrm{T}}$ at the center, $\left[4.625 \times 10^{-6}-4.625 \times 10^{-6} 0\right]^{\mathrm{T}}$ $\mathrm{m}$ to the left and slightly ahead, and $\left[-4.625 \times 10^{-6}\right.$ $\left.4.625 \times 10^{-6} 0\right]^{\mathrm{T}} \mathrm{m}$ to the right and slightly behind. The bacteria are initially $1 \times 10^{-2} \mathrm{~m}$ away from the bottom surface of the Neodymium magnet while swimming at a proximity of $0.5 \times 10^{-6} \mathrm{~m}$ to the boundary of the liquid medium. The stationary surface that is taken to be flat in this study. The simulation interval is set to be $t=\left[\begin{array}{ll}0 & 3\end{array}\right] \mathrm{s}$ in real time. The tuning parameters for the PID controller are set to be $K_{p 31}=0.1, K_{p 32}=0.1$, $K_{i 32}=0.02, K_{p 33}=0.1, K_{i 33}=0.02, K_{p-x}=75, K_{i a-x}=$ $5, K_{p-y}=75, K_{i a^{-y}}=5, K_{d-x}=0.1$, and $K_{d-y}=0.1$, on both accounts. All results are obtained by variable step solver ode45, under MATLAB/SIMULINK environment.
Figure 3 is the result of the clockwise and counterclockwise rotation control studies. The former exhibits spatial overshoots on the orientation of the swarm whereas the latter exhibits a phase delay, i.e., a spatial resistance to the rigid-body rotation. The fact that two different behaviors are observed is based on the direction of the rotation of the helical tails. As the helical tails rotate in the counter-clockwise direction, it is arguably much easier to rotate the swarm itself in the clockwise direction in the lab frame; a response arising due to the hydrodynamic interaction between the solid boundary and the rotating helical tail of each bacterium [54] that in turn affects the whole swarm.
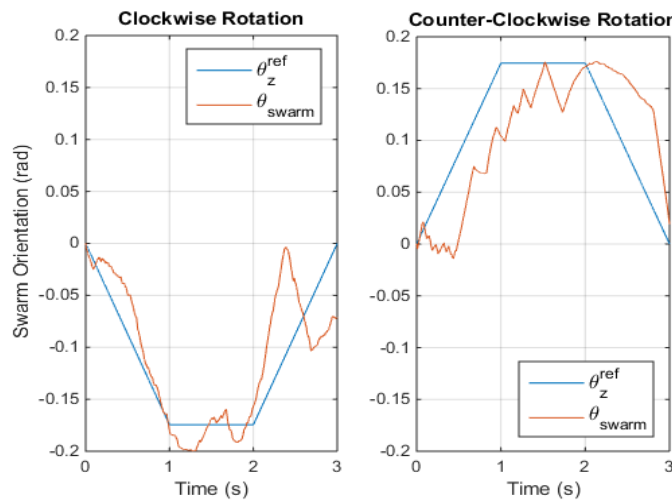

Figure 3. The orientation of the swarm under clockwise and counter-clockwise rigid-body rotation control in the lab-frame.

Figure 4 represents the PWM signals on the dedicated DC-motors at the respective joints of the PPR arm. Only the $\mathrm{x}$-axis performances are observed to be akin to one another whereas the performances on the y-axis and the $\mathrm{z}$-axis are almost the opposite as expected. It can be further observed that the PWM signals dictate the direction of rotation. It is also important to note that the PWM signals are not continuous but exhibit impulse function characteristics due to the incremental change in the reference signal over simulation time.
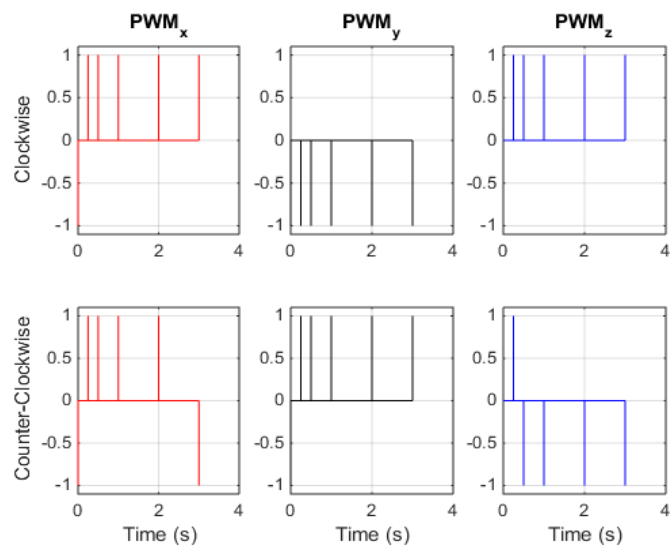

Figure 4. The dedicated PWM signals are generated on the $\mathrm{x}, \mathrm{y}$, and $\mathrm{z}$ axes of the PPR arm under clockwise and counter-clockwise rigid-body rotation control in the lab-frame. 
Figure 5 depicts the currents on the dedicated DCmotors. The observed behavior mirrors the PWM signals, as expected. The currents along the $\mathrm{x}$-axis and $\mathrm{y}$-axis never exceeds $0.01 \mathrm{~A}$; however, the extrema for the $\mathrm{z}$-axis reaches $\pm 0.02 \mathrm{~A}$, although not shown in the figures to preserve the overall resolution. The sudden jerk [55] in the rotation to match the reference angle is the direct cause of this behavior.
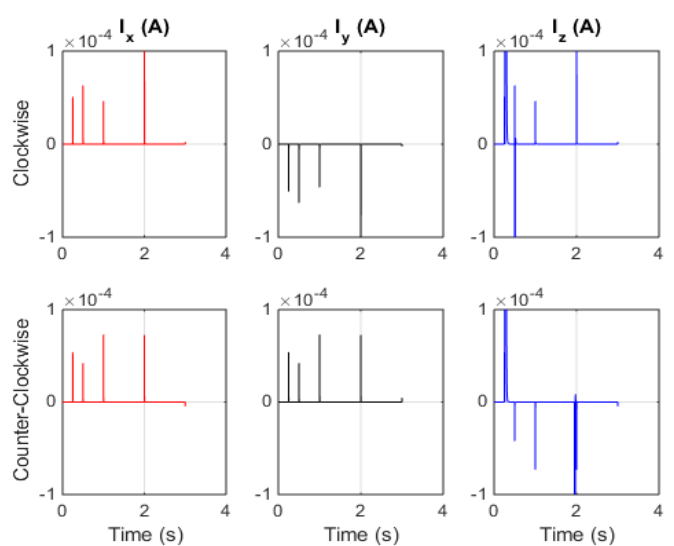

Figure 5. Dedicated DC-motor currents generated on the $\mathrm{x}, \mathrm{y}$, and $\mathrm{z}$ axes of the PPR arm under clockwise and counter-clockwise rigid-body rotation control in the lab-frame.

Figure 6 illustrates how the magnetic torque is adequate to rotate the swarm. The average of the propulsive torque, $\left\langle\mathrm{T}_{\mathrm{p}, \mathrm{z}}\right\rangle$, on the entire swarm is oscillating around zero meaning that it attains zero N.m several times per period. In the meantime, the average of the magnetic torque on the swarm, $\left\langle\mathrm{T}_{\mathrm{m}, \mathrm{z}}\right\rangle$, is seldom zero. It follows that, although the extrema of the magnetic torque are overwhelmed by the extrema of the propulsive torque, the magnetic torque is constant long enough to overcome the propulsive torque. It is important to note that, this analysis assumes that the magnetic torque can overcome Brownian noise [56]; an analysis previously carried out in detail for Magnetospirillum Gryphiswaldense MSR-1 and Neodymium magnet [28].
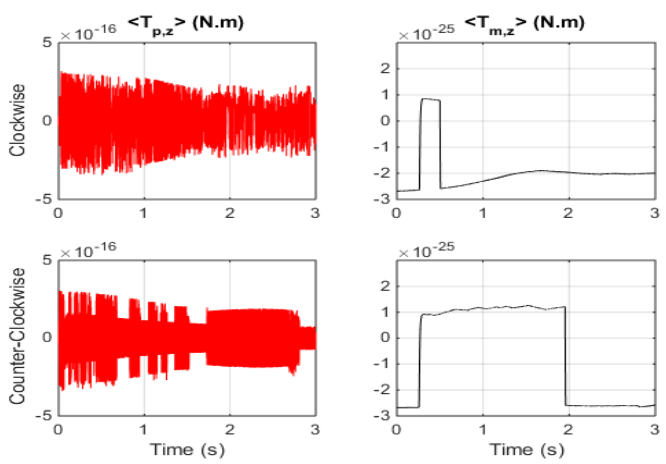

Figure 6. The average of the propulsive torque induced by and magnetic torque exerted on the swarm, both along the z-axis, under clockwise and counterclockwise rigid-body rotation control in the lab-frame.
Finally, Figure 7 depicts the net repulsive force acting on the bacterium cell at the center over simulation time. It is known that two micro-objects moving and rotating in close formation will affect each other $[50,57,58]$. The force-components are calculated in the frame of the bacterium, i.e., the forward propulsive force is along the $\mathrm{x}$-axis. The repulsive effect modeled here exhibits that the additional force along the direction of swimming has a net contribution to the $\mathrm{x}$ traverse of the bacterium at the center. On the other hand, the lateral force along the swimming direction, i.e., y-axis, exhibits a swing in the direction as the swarm rotates.
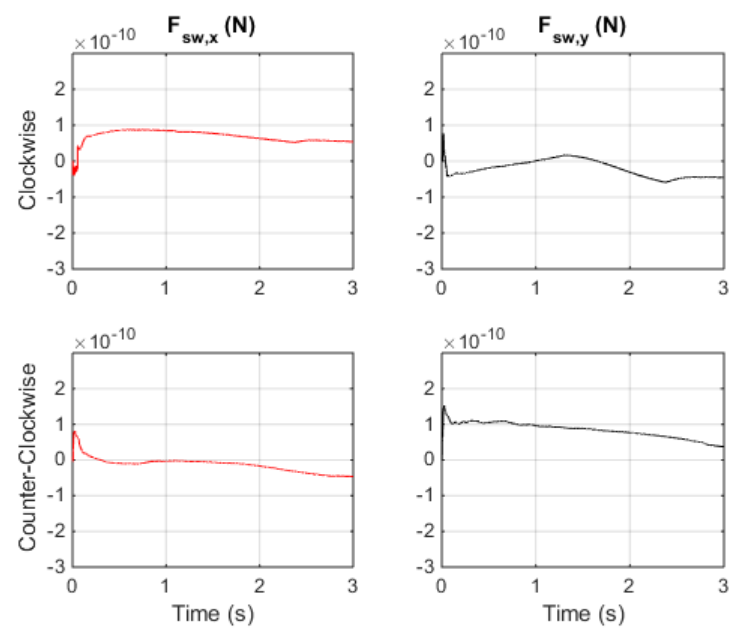

Figure 7. The total repulsion force exerted on the bacterium cell in the middle of the task-group, along the $\mathrm{x}$-axis and $\mathrm{y}$-axis of the frame of the bacterium, under clockwise and counter-clockwise rigid-body rotation control in the lab-frame.

\section{CONCLUSION}

The swarm motion in complex biological fluids is of interest due to the envisioned application of swimming micro-robotic swarms, artificial or cybernetic. The study here focuses on the dynamics of three magnetotactic bacteria initially separated from each other at a certain distance and moving as a task force in the synovial fluid of a human at body temperature. The PID control scheme is set to be adaptive on the integral gain to reduce the steady-state error on the yaw-angle while the reference signal is set as discontinuous functions of time. The results show that (i) it is possible to control the swimming direction of a swarm of bacterial and (ii) the repulsive force has a measurable contribution to the force balance.

The study should be replicated for a relatively larger group of bacteria to see the effect of the repulsive force in all main axes. Furthermore, such a simulation study would also help on the effective volume of interest on which the magnetic field is focused. Finally, the study should be replicated under actual dimensions of a synovial joint to imitate the in vivo conditions as much as possible to further study the overall swimming dynamics of the swarm. The results 
will be beneficial for the micro-robotic research community as well as the medical science, in the future.

Synovial joints are relatively safer in terms of flow conditions and immune system reactions given that they do not posses blood vessels. The microrobot, artificial or biohybrid, will arguably be subject to less biophysical and biochemical stimuli [59]. Thus, swarms of microrobots can be utilized in synoval cavity for minimally invasive biomedical applications while the patient, or the joint of interest, is stationary without load for the duration of the procedure. A very comparable promising field of application is ophthalmetry [60] where the eye offers a similar biophysical work environment, i.e., non-Newtonian flow with no motion, inspite of presence of blood vessels. In both cases, the flow field is none existent, except for the field induced by the swarm, and the location of the tissuse renders the procedure easier for relatively weaker magnetic fieds to penetrate in adequate strength to acuate and steer microrobots. Therefore, micro-robotic swarm can carry drugs or cells to repair tissue directly on targetted locations $[13,19]$ increasing the effectiveness of the treatment and decreasing the time of recovery.

\section{REFERENCES}

[1] Agrahari, V., Agrahari, V., Chou, M.-L., Chew, C. H., Noll, J., \& Burnouf, T. (2020). Intelligent Micro-/Nanorobots as Drug and Cell Carrier Devices for Biomedical Therapeutic Advancement: Promising Development Opportunities and Translational Challenges. Biomaterials, 260, 120163.

[2] Cabanach, P., Pena- Francesch, A., Sheehan, D., Bozuyuk, U., Yasa, O., Borros, S., \& Sitti, M. (2020). Microrobots: Zwitterionic 3D- Printed Non- Immunogenic Stealth Microrobots. Advanced Materials, 32(42), 2070312.

[3] Ebrahimi, N., Bi, C., Cappelleri, D. J., Ciuti, G., Conn, A. T., Faivre, D., Habibi, N., Hošovský, A., Iacovacci, V., Khalil, I. S. M., Magdanz, V., Misra, S., Pawashe, C., Rashidifar, R., Soto- Rodriguez, P. E. D., Fekete, Z., \& Jafari, A. (2020). Magnetic Actuation Methods in Bio/Soft Robotics. Advanced Functional Materials, 2005137.

[4] Field, R. D., Anandakumaran, P. N., \& Sia, S. K. (2019). Soft medical microrobots: Design components and system integration. Applied Physics Reviews, 6(4), 041305.

[5] Ghosh, A., Xu, W., Gupta, N., \& Gracias, D. H. (2020). Active Matter Therapeutics. Nano Today, 31, 100836.

[6] Gunduz, S., Albadawi, H., \& Oklu, R. (2020). Robotic Devices for Minimally Invasive Endovascular Interventions: A New Dawn for Interventional Radiology. Advanced Intelligent Systems, 2000181
[7] Hu, M., Ge, X., Chen, X., Mao, W., Qian, X., \& Yuan, W.-E. (2020). Micro/Nanorobot: A Promising Targeted Drug Delivery System. Pharmaceutics, 12(7), 665.

[8] Hunter, E. E., Brink, E. W., Steager, E. B., \& Kumar, V. (2018). Toward Soft Micro Bio Robots for Cellular and Chemical Delivery. IEEE Robotics and Automation Letters, 3(3), 1592-1599.

[9] Soto, F., Wang, J., Ahmed, R., \& Demirci, U. (2020). Medical Micro/Nanorobots in Precision Medicine. Advanced Science, 7(21), 2002203.

[10] Wang, J., Dong, R., Wu, H., Cai, Y., \& Ren, B. (2019). A Review on Artificial Micro/Nanomotors for Cancer-Targeted Delivery, Diagnosis, and Therapy. Nano-Micro Letters, 12(1), 1-19.

[11] Bogue, R. (2008). The Development of Medical Microrobots: A Review of Progress. Industrial Robotics, 35(4), 294-299.

[12] Felfoul, O., Martel, S. (2013). Assessment of Navigation Control Strategy for Magnetotactic Bacteria in Microchannel: Toward Targeting Solid Tumors. Biomedical Microdevices, 15(6), 1015-1024.

[13] Yasa, C., Tabak, A. F., Yasa, O., Ceylan, H., Sitti, m. (2019). 3D-Printed Microrobotic Transporters with Recapitulated Stem Cell Niche for Programmable and Active Drug Delivery. Advanced Functional Materials, 29(17), 1808992.

[14] Qiu, F., Nelson, B. J. (2015). Magnetic Helical Micro- and Nanorobots: Toward Biomedical Applications. Engineering, 1(1), 21-26.

[15] Ghosh, A., Fischer, P. (2009). Controlled Propulsion of Artificial Magnetic Nanostructured Propellers. Nano Letters, 9(6), 2243-2245.

[16] Dreyfus, R., Baudry, J., Roper, M. L., Fermigier, M., Stone, H. A., Bibette, J. (2005) Microscopic Artificial Swimmer, Nature, 437, 862-865.

[17] Williams, B. J., Anand, S. V., Rajagopalan, J., Saif, M. T. A. (2014). A Self-Propelled Biohybrid Swimmer at Low Reynolds Number, Nature Communications, 5, 3081.

[18] Xiong, X., Lidstrom, M. E., Parviz, B. A. (2007). Microorganisms for MEMS. Journal of Microelectromechanical Systems, 16(2), 429444.

[19] Alapan, Y., Yasa, O., Schauer, O., Giltinan, J., Tabak, A. F., Sourjik, V., Sitti M. (2018). Soft Erythrocyte-Based Bacterial Microswimmers for Cargo Delivery. Science Robotics, 3(17), eaar4423.

[20] Yasa, I. C., Ceylan, H., Bozuyuk, U., Wild, A.M., \& Sitti, M. (2020). Elucidating the Interaction Dynamics Between Microswimmer Body and Immune System for Medical 
Microrobots. Science Robotics, 5(43), eaaz3867.

[21] Park, H., \& Park, K. (1996). Biocompatibility Issues of Implantable Drug Delivery Systems. Pharmaceutical Research, 13(12), 1770-1776.

[22] Horie, M., Fujita, K., Kato, H., Endoh, S., Nishio, K., Komaba, L. K., Nakamura, A., Miyauchi, A., Kinugasa, S., Hagihara, Y., Niki, E., Yoshida, Y., \& Iwahashi, H. (2012). Association of the Physical and Chemical Properties and the Cytotoxicity of Metal Oxide Nanoparticles: Metal Ion Release, Adsorption Ability and Specific Surface Area. Metallomics, 4(4), 350.

[23] Ceylan, H., Yasa, I. C., Tabak, A. F., Giltinan, J., Sitti, M. (2019). 3D-Printed Biodegradable Microswimmer for Theranostic Cargo Delivery and Release. ACS Nano, 13(3), 3353-3362.

[24] Uenoyama, A., Miyata, M. (2005). Gliding Ghosts of Mycoplasma Mobile. Proceedings of the National Academy of Sciences USA, 102(36), 12754-12758.

[25] Patiño, T., Feiner-Gracia, N., Arqué, X., MiguelLópez, A., Jannasch, A., Stumpp, T., Schäffer, E., Albertazzi, L., \& Sánchez, S. (2018). Influence of Enzyme Quantity and Distribution on the Self-Propulsion of Non-Janus UreasePowered Micromotors. Journal of the American Chemical Society, 140(25), 78967903.

[26] Sun, H. C. M., Liao, P., Wei, T., Zhang, L., \& Sun, D. (2020). Magnetically Powered Biodegradable Microswimmers. Micromachines, 11(4), 404.

[27] Go, G., Jeong, S.-G., Yoo, A., Han, J., Kang, B., Kim, S., Nguyen, K. T., Jin, Z., Kim, C.-S., Seo, Y. R., Kang, J. Y., Na, J. Y., Song, E. K., Jeong, Y., Seon, J. K., Park, J.-O., \& Choi, E. (2020). Human Adipose-Derived Mesenchymal Stem Cell-Based Medical Microrobot System for Knee Cartilage Regeneration In Vivo. Science Robotics, 5(38), eaay6626.

[28] Tabak, A. F. (2020). Bilateral Control Simulations for a Pair of Magnetically-Coupled Robotic Arm and Bacterium for In Vivo Applications. Journal of Micro-Bio Robotics, 16(2), 199-214.

[29] Ahmed, D., Sukhov, A., Hauri, D., Rodrigue, D., Maranta, G., Harting, J., \& Nelson, B. J. (2021). Bioinspired Acousto-Magnetic Microswarm Robots with Upstream Motility. Nature Machine Intelligence, 1.

[30] Dong, X., \& Sitti, M. (2020). Controlling TwoDimensional Collective Formation and Cooperative Behavior of Magnetic Microrobot Swarms. The International Journal of Robotics Research, 39(5), 617-638.

[31] Keya, J. J., Kabir, A. M. R., Inoue, D., Sada, K., Hess, H., Kuzuya, A., \& Kakugo, A. (2018).
Control of Swarming of Molecular Robots. Scientific Reports, 8(1), 1-10.

[32] Mirzakhanloo, M., \& Alam, M.-R. (2020). Stealthy Movements and Concealed Swarms of Swimming micro-robots. Physics of Fluids, 32(7), 071901.

[33] Morozov, K. I., \& Leshansky, A. M. (2020). Towards Focusing of a Swarm of Magnetic Micro/Nanomotors. Physical Chemistry Chemical Physics, 22(28), 16407-16420.

[34] Servant, A., Qiu, F., Mazza, M., Kostarelos, K., \& Nelson, B. J. (2015). Controlled In Vivo Swimming of a Swarm of Bacteria- Like Microrobotic Flagella. Advanced Materials, 27(19), 2981-2988.

[35] Xu, T., Soto, F., Gao, W., Dong, R., GarciaGradilla, V., Magaña, E., Zhang, X., \& Wang, J. (2015). Reversible Swarming and Separation of Self-Propelled Chemically Powered Nanomotors under Acoustic Fields. Journal of the American Chemical Society, 137(6), 21632166.

[36] Yousefi, M., \& Nejat Pishkenari, H. (2021). Independent Position Xontrol of Two Identical Magnetic Microrobots in a Plane Using Rotating Permanent Magnets. Journal of Micro-Bio Robotics, 1-9.

[37] Johnson, B. V., Esantsi, N., \& Cappelleri, D. J. (2020). Design of the $\mu$ MAZE Platform and Microrobots for Independent Control and Micromanipulation Tasks. IEEE Robotics and Automation Letters, 5(4), 5677-5684.

[38] Khalil, I. S. M., Tabak, A. F., Hamed, Y., Tawakol, M., Klingner, A., Gohary, N. E., Mizaikoff, B., \& Sitti, M. (2018). Independent Actuation of Two-Tailed Microrobots. IEEE Robotics and Automation Letters, 3(3), 17031710.

[39] Khalil, I. S. M., Pichel, M. P., Abelmann, L., \& Misra, S. (2013). Closed-loop control of magnetotactic bacteria. The International Journal of Robotics Research, 32(6), 637-649.

[40] Khalil, I. S. M., Tabak, A. F., Hageman, T., Ewis, M., Pichel, M., Mitwally, M. E., El-Din, N. S., Abelmann, L., \& Sitti, M. (2017). Near-surface effects on the controlled motion of magnetotactic bacteria. 2017 IEEE International Conference on Robotics and Automation (ICRA).

[41] Tabak, A. F. (2020). Motion Control for Biohybrid Multiscale Robots. 2020 Innovations in Intelligent Systems and Applications Conference (ASYU).

[42] Tabak, A. F. (2020). Adaptive Motion Control of Modified E. Coli. 2020 International Congress on Human-Computer Interaction, Optimization and Robotic Applications (HORA).

[43] Tabak, A. F. (2020). A Simulated Control Method for a Magnetically-Coupled Bacterium and Robotic Arm. 2020 International 
Conference on Manipulation, Automation and Robotics at Small Scales (MARSS).

[44] Tabak, A. F. (2020). Simulated Bilateral Motion Control of a Magneto-Tactic Bacterium via an Open Kinematic Chain. 2020 17th International Conference on Ubiquitous Robots (UR).

[45] Tabak, A. F. (2020). Independent Joint Control Simulations on Adaptive Maneuvering of a Magnetotactic Bacterium via a Single Permanent Magnet. European Journal of Science and Technology, 50-59.

[46] Dong, F., Huang, Z., Qiu, D., Hao, L., Wu, W., \& Jin, Z. (2019). Design and Analysis of a SmallScale Linear Propulsion System for Maglev Applications (1) - The Overall Design Process. IEEE Transactions on Applied Superconductivity, 29(2), 1-5.

[47] Maxon Motor Product Catalog. Https://Www.Maxongroup.Com. Retrieved February 13, 2021, from https://www.maxongroup.com/maxon/view/pro duct $/ 397172$

[48] Tabak, A. F. (2018). Hydrodynamic Impedance of Bacteria and Bacteria-Inspired MicroSwimmers: A New Strategy to Predict Power Consumption of Swimming Micro-Robots for Real-Time Applications. Advanced Theory and Simulations, 1(4), 1700013.

[49] Brennen, C., \& Winet, H. (1977). Fluid Mechanics of Propulsion by Cilia and Flagella. Annual Review of Fluid Mechanics, 9(1), 339398.

[50] Ishikawa, T., Sekiya, G., Imai, Y., \& Yamaguchi, T. (2007). Hydrodynamic Interactions between Two Swimming Bacteria. Biophysical Journal, 93(6), 2217-2225.

[51] Spong, M. W., \& Vidyasagar, M. (1989). Robot Dynamics and Control (1st ed.). Wiley.

[52] Mazzucco, D., McKinley, G., Scott, R. D., \& Spector, M. (2002). Rheology of Joint Fluid in
Total Knee Arthroplasty Patients. Journal of Orthopaedic Research, 20(6), 1157-1163.

[53] Smith, A. M., Fleming, L., Wudebwe, U., Bowen, J., \& Grover, L. M. (2014). Development of a Synovial Fluid Analogue with Bio-Relevant Rheology for Wear Testing of Orthopaedic Implants. Journal of the Mechanical Behavior of Biomedical Materials, 32, 177-184.

[54] Lauga, E., DiLuzio, W. R., Whitesides, G. M., \& Stone, H. A. (2006). Swimming in Circles: Motion of Bacteria near Solid Boundaries. Biophysical Journal, 90(2), 400-412.

[55] Eager, D., Pendrill, A.-M., \& Reistad, N. (2016). Beyond Velocity and Acceleration: Jerk, Snap and Higher Derivatives. European Journal of Physics, 37(6), 065008.

[56] Ghosh, A., \& Fischer, P. (2009). Controlled Propulsion of Artificial Magnetic Nanostructured Propellers. Nano Letters, 9(6), 2243-2245.

[57] Goldfriend, T., Diamant, H., \& Witten, T. A. (2015). Hydrodynamic Interactions between Two Forced Objects of Arbitrary Shape. I. Effect on Alignment. Physics of Fluids, 27(12), 123303.

[58] Goldfriend, T., Diamant, H., \& Witten, T. A. (2016). Hydrodynamic Interactions between two Forced Objects of Arbitrary Shape. II. Relative Translation. Physical Review E, 93(4), 042609.

[59] Kuettner, K., \& Cole, A. (2005). Cartilage Degeneration in Different Human Joints. Osteoarthritis and Cartilage, 13(2), 93-103.

[60] Ullrich, F., Fusco, S., Chatzipirpiridis, G., Pané, S., \& Nelson, B. J. (2014). Recent Progress in Magnetically Actuated Microrobotics for Ophthalmic Therapies. European Ophthalmic Review, 08(02), 120. 